\title{
"Nós, professores, temos uma obrigação quase moral de nos aproximarmos das novas tecnologias e compreendê-las"
}

\author{
Ivan Bomfim (UEPG)' \\ Karine Vieira (Uninter)²
}

O espanhol Ramón Salaverría é um dos principais nomes mundiais no âmbito das pesquisas em ciberjornalismo. Docente da Faculdade de Comunicação da Universidade de Navarra (Espanha) e diretor do Center for Internet Studies and Digital Life, Salaverría também atuou como professor-visitante na University do Texas em Austin (EUA), diretor da Journalism Studies Section da ECREA e membro da World Journalism Education Council, dentre outras atividades. Em 2012, lecionou pela Organização das Nações Unidas para o diretório Global Experts, que inclui especialistas mundiais em distintas disciplinas. Publicou e organizou diversas obras, como Ciberperiodismo en Iberoamérica (2016), Cibermedios (2005), Redacción periodística en internet (2005) e Manual de redacción ciberperiodística (2003).

Nesta conversa com a Pauta Geral, Salaverría analisa as relações entre investigação em jornalismo e o avanço tecnológico na contemporaneidade, buscando compreender como pesquisadores podem abordar este novo cenário. Ademais, o acadêmico espanhol reflete acerca de seu percurso pessoal em perspectiva aos estudos dos cibermeios jornalísticos no espaço da lbero-América.

\footnotetext{
1 Professor do Departamento de Jornalismo e do Mestrado em Jornalismo da Universidade Estadual de Ponta Grossa (UEPG). É um dos coordenadores do Grupo de Estudos e Pesquisas em Mídias Digitais (GEMIDI). Doutor em Comunicação e Informação pela Universidade Federal do Rio Grande do Sul. E-mail: ivanbp17@gmal.com.

2 Professora do Departamento de Jornalismo do Centro Universitário Internacional (Uninter). É coordenadora do Grupo de Pesquisa Inovação e Empreendedorismo nos Cursos de Jornalismo - Brasil e Portugal. Doutora em Ciências da Comunicação pela Universidade do Vale do Rio dos Sinos (Unisinos). E-mail: karinemourav@gmail.com.
}

Revista Pauta Geral-Estudos em Jornalismo, Ponta Grossa, vol. 6, n. 1, p. 166-183, Jan/Jun, 2019. 
Pauta Geral (PG): 0 sr. atualmente é um dos maiores pesquisadores da área de Jornalismo, convergência e novas tecnologias. Como começou a sua trajetória?

Ramón Salaverría: Sou um jornalista, me considero um jornalista. Sublinho isso porque há, atualmente, pessoas que estão trabalhando com os meios de comunicação digitais que procedem de outras origens, procedem do âmbito tecnológico, do marketing, do mundo empresarial... e em meu caso, minha origem é jornalística, estudei Jornalismo na Universidade de Navarra ${ }^{3}$. Desde cedo, tinha uma vocação jornalística, e trabalhei alguns anos como jornalista, inclusive nos anos 1990 - obviamente, não em meios digitais, que ainda não havia chegado na Espanha. Mas, uma vez terminado esse período, tendo uma experiência não muito grande (foram dois ou três anos na redação, principalmente no rádio e em agências), eu recebi o convite por parte da Universidade de Navarra para poder fazer uma tese de doutoramento, me ofereceram uma bolsa. Bom, nunca havia pensado nesta opção, pois tinha uma vocação jornalística muito marcada, mas também

3 Instituição localizada na cidade de Pamplona, Espanha. considerei que a oportunidade de fazer um doutorado com bolsa seria única, algo que não teria nunca mais. Então comecei a fazer a tese, inicialmente sem muito

convencimento de que aquilo

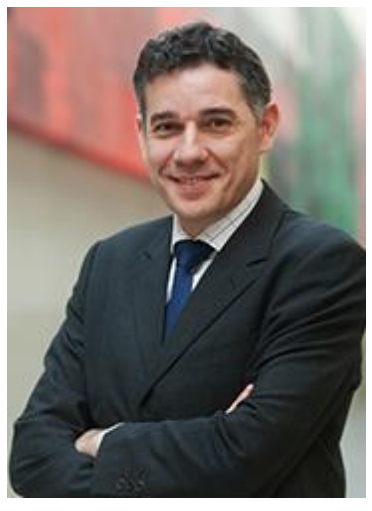
poderia terminar sendo meu futuro profissional. Mas, quando comecei a realizar a investigação, me dei conta de que aquilo me produzia uma grande satisfação, porque frente ao tipo de trabalho jornalístico que se esgota muito rapidamente, o trabalho de investigação no mundo universitário é um tipo de trabalho muito mais profundo, muito mais exaustivo, e eu gostava de esse tipo de investigação mais aprofundada. Por outro lado, orientei meus estudos em direção a uma área que estava nascendo.

Eu tive a sorte, neste caso, de coincidir temporalmente com o nascimento dos primeiros meios digitais. Comecei a fazer minha tese de doutorado no ano de 1993, há pouco mais de 25 anos. E justo imediatamente depois que eu comecei a fazer minha tese começaram os primeiros movimentos de meios digitais na Espanha, com os quais acabei tendo

Revista Pauta Geral-Estudos em Jornalismo, Ponta Grossa, vol. 6, n. 1, p. 166-183, Jan/Jun, 2019. 
o privilégio de acompanhar, literalmente, todo o percurso dos meios digitais na Espanha. Assisti ao nascimento e evolução desses meios. Em comparação a outras investigadores, que centram sua atenção a um assunto determinado e depois mudam para um assunto distinto, penso que uma das minhas características que sempre teve minhas investigações é este foco: desde o início, me interessei pelos meios digitais, e sempre segui esta linha. Sem dúvida, em função de minha origem estritamente jornalística, eu sempre coloquei o jornalismo à frente do digital. Em algumas ocasiões, na expressão "jornalismo digital", o primeiro termo é o substantivo, "digital" é o adjetivo. E a gramática nos ensina que 0 adjetivo complementa o substantivo, não o inverso. Entendo que a tecnologia digital está a serviço do jornalismo.

PG: Como foi, no início dos anos 2000, o início da produção acadêmica sobre o ciberjornalismo, tendo em vista que era um assunto em nascimento?

Ramón Salaverría: Foi um momento curioso porque nós, da Faculdade de Comunicação de Navarra, fundamos em 1995 o primeiro laboratório de comunicação multimídia da Espanha. Não sei se existia na época alguma na América Latina, creio que não. Era um laboratório que tinha como foco a experimentação com as narrativas mas, também, sobretudo uma vocação de investigação, de dar conta analiticamente deste novo fenômeno que estava nascendo. Fizemos isso a partir de pequenos seminários, organizamos alguns congressos, trouxemos pessoas de outros países, dos EUA, porque não tínhamos muito o que oferecer (estou falando dos anos 95, 96, 97), nós mesmos não havíamos feito investigações naquele momento. $E$ minha experiência a partir dos anos 1997, 1998 - era muito jovem, tinha por volta de 26, 27, 28 anos -, quando começo a participar de pequenos congressos, e apresentando minhas primeiras pesquisas e comunicações, era um âmbito absolutamente marginal dentro dos estudos de comunicação. Não tinha nada a ver com o que é hoje. Atualmente, quando alguém vai a um evento da área, uma porcentagem absolutamente majoritária tem relação com investigações do mundo digital. $\mathrm{E}$ naquele momento, era excepcional quando encontrava-se com algum pesquisador que estivesse fazendo algo parecido com o que você estava. 
Então, certamente o que ocorreu é que alguns poucos investigadores, com características em comuns - jovens, isolados em sua própria faculdade porque não havia equipes de investigação, sendo pessoas que trabalhavam, em grande medida, de maneira independente - fomos nos encontrando em eventos da temática. $E$ a partir deste encontro, visto que surgiram amizades, surgiu também uma intenção de colaboração, porque vimos que todos estávamos em uma situação bastante parecida. Dissemos: "bom, se não temos interlocutores na faculdade, vamos buscá-los em outras universidades". A partir daí, iniciamos uma coordenação para apresentar um primeiro projeto de investigação na Espanha. E enquanto estávamos fazendo isso, houve uma chamada de uma rede europeia para nós aqui em Navarra - o que é uma coisa bastante curiosa: antes de termos um projeto nacional, fizemos parte de um projeto internacional. Então, a situação de ter feito parte de um projeto internacional abre portas para financiamento em seu próprio país (creio que no Brasil passa algo parecido). Fruto da participação neste projeto, foram seguindo as primeiras publicações, como o Manual de Redação Ciberjornalística, em 2003.
PG: Do início do século $X X I$, damos um salto até o final desta segunda década. Recentemente (2016), o senhor publicou um estudo sobre os cibermeios na lberoamérica, no qual são tratadas questões relativas ao desenvolvimento das mídias jornalísticas nos países da América Latina, na Espanha e em Portugal. Diversos autores trazem investigações sobre o cenário em seus países (no caso do Brasil, a autora é a professora Suzana Barbosa ${ }^{4}$ ). No livro, o senhor diz que, de forma geral, de meios secundários, os cibermeios passaram de secundários a protagonistas, e essa mudança, no caso da Ibero-América, é relativa ao grau de tecnologização de cada sociedade. Como o senhor vê o avanço das tecnologias digitais em conjunto desses países, e as principais similaridades e diferenças?

Ramón Salaverría: Permita-me um preâmbulo para explicar porque escrevi esse livro. Das coisas que pesquisei e publiquei, é a obra com a qual estou

4 Professora do Departamento de Comunicação e do Programa de PósGraduação em Comunicação e Cultura Contemporâneas da Faculdade de Comunicação da Universidade Federal da Bahia.

Revista Pauta Geral-Estudos em Jornalismo, Ponta Grossa, vol. 6, n. 1, p. 166-183, Jan/Jun, 2019. 
mais satisfeito. Me parece ser minha principal contribuição. Há outras contribuições de cunho teórico, conceitual, mas esta é mais de tipo histórico. Fiz essa obra porque tinha uma espécie de dívida com a investigação sobre ciberjornalismo na iberoamérica. Quando comecei a estudar os meios digitais nos anos 1990, analisei, junto a outros investigadores, as características, as magnitudes, as modalidades dos meios digitais na Espanha, os perfis profissionais, esse tipo de coisa. De modo que cumprida a primeira década (entre 1995 e 2005), fizemos uma primeira análise grande sobre a evolução dos meios digitais no país. Posteriormente, ao ser orientador de teses de doutorado - por exemplo, orientei um trabalho de doutoramento sobre ciberjornalismo no Peru, foi a primeira realizada sobre essa questão também colaborei com colegas do Brasil como Suzana Barbosa e Marcos Palacios $^{5}$, pesquisadores pioneiros nesta disciplina. Então me dei conta que passava o tempo e na América Latina não havia nenhum estudo que analisava

5 Professor do Departamento de Comunicação e do Programa de PósGraduação em Comunicação e Cultura Contemporâneas da Faculdade de Comunicação da Universidade Federal da Bahia. o fenômeno em seu conjunto. Alguns países (não todos) contavam com pequenos estudos - muitas vezes, simples estudos de caso ou investigações parciais sobre um território, nem sequer um país completo - mas não havia uma visão da região latinoamericana. Nem as grandes faculdades de Comunicação ou organizações de investigadores, como FELAFACS ou FACOM, haviam feito uma coordenação para a realização desse trabalho, o que seria o lógico. É um tanto ilógico e surpreendente que este livro tenha sido feito na Espanha.

Pensei que era uma obrigação praticamente moral fazer esta pesquisa porque senão muita informação seria perdida. Havia países da América Central, do Caribe e andinos, por exemplo, que até a publicação do livro não tinham nenhum tipo de estudo minimamente estruturado, nem mesmo um simples trabalho acadêmico sobre as características e perfis dos meios digitais deste país. Portanto, determinei que esse livro não poderia se concentrar nos "grandes países" (entendendo pelo termo os países com maior população ou desenvolvimento econômico). Pareceume uma questão de justiça que todos os países, independente do desenvolvimento econômico, da 
dimensão territorial e da população deveriam estar representados neste livro. $E$ a verdade é que se conseguiu, não? É uma publicação que inclui os 22 países ibero-americanos de língua espanhola e portuguesa. A partir daí, tentei localizar pessoas que pudessem me ajudar, tendo em vista que era um projeto muito complexo - sobretudo por ter a necessidade de haver uma estrutura comum, os autores seguiram determinados padrões específicos de produção.

A respeito da assunção de protagonismo dos cibermeios, é verdade que há uma razão tecnológica, um fator tecnológico que contribuiu ao seu fortalecimento. Mas não é o único fator. Não sei se é o principal. Há outros motivos de tipo social, econômico, profissional, mesmo de tipo cultural que condicionaram um fortalecimento dos meios digitais. Quando faço referência a fatores de tipo social, incluo aí também a dimensão política, pois nos últimos quinze anos, os países ibero e, especialmente, latinoamericanos passaram, em geral, por processos de consolidação de regimes democráticos (em contrário às situações de ditadura que existiram antes dos anos 1990). Também houve um pronunciado desenvolvimento econômico na região, mesmo que com grandes diferenças - em alguns casos, posteriormente frustrados, como por exemplo o Brasil, que cresceu muito mas que, depois, sofreu uma parada econômica e política bastante forte nos últimos anos. Mas, em todo caso, visto em conjunto, foram duas décadas nas quais a liberdade se forteleceu na América Latina, com um fortalecimento econômico que, por outro lado, aconteceu com grandes injustiças ao mesmo tempo.

Neste cenário de fortalecimento econômico, desenvolvimento tecnológico e das comunicações e também uma certa desigualdade político, houve certamente o surgimento de novas vozes frente às hegemônicas dos meios anteriormente consolidadas (os grandes jornais e cadeias de televisão e rádio). Emergiu uma série de novos atores que, embora não tenham uma importância equiparável à dos grandes atores midiáticos, alcançaram significativa influência. Há alguns países nos quais esses meios nativos digitais já são absolutamente relevantes nas dinâmicas da informação pública e política, como no México, na Colômbia, no Chile, na Venezuela, mesmo em Cuba - apesar do controle férreo por parte do governo socialista a respeito dos meios, há alguns digitais que começam a publicar estando de fora quanto de dentro da ilha, 
a dissidência política se expressa não em periódicos, não na TV, não no rádio, mas sim através da internet.

Desde este ponto de vista, eu vejo nos meios digitais um crescente protagonismo como alternativa aos discursos hegemônicos nos meios tradicionais. Eles ampliaram o âmbito do discurso público, neste sentido. Houve também razões econômicas que, em meu modo de ver, respaldaram e fortaleceram essas dinâmicas relacionadas aos cibermeios. Curiosamente, por uma parte, o crescimento econômico e a extensão das telecomunicações é evidentemente algo que possibilita o desenvolvimento dos meios digitais, mas posteriormente a crise econômica - e a crise que afetou às empresas de comunicação paradoxalmente eu creio que foi algo positivo para o desenvolvimento dos meios digitais. Por quê? Porque há muitos jornalistas que estavam à margem da indústria jornalística que perderam seu trabalho, mas que não perderam 0 interesse em seguir informando. E, neste contexto, encontraram a possibilidade de seguir desenvolvendo sua atividade profissional nos meios digitais com menos custos, um funcionamento muito mais econômico do que os dos meios tradicionais.
Então, há um conjunto de fatores diversos que propiciaram a emergência de um novo fenômeno que, todavia, vejo como incipiente, pois já se faz perceber, mas ainda não alcançou seu máximo desenvolvimento. $\mathrm{E}$ assim, tenho a impressão de que, nesta terceira década dos meios digitais, uma das principais transformações que serão percebidas no âmbito da América Latina e sua relação com o jornalismo será precisamente esta: o notável fortalecimento dos meios nativos digitais.

Em relação à segunda pergunta (as similitudes e as diferenças), penso que, apesar do que normalmente é dito de que os "meios digitais são revolucionários" em relação ao que existia anteriormente, é verdade que há tanto mudanças quantitativas, mas também qualitativas na forma com que se realiza o jornalismo. Vendo as coisas com uma certa distância (que é o que eu tento fazer), é verdade que aconteceram mudanças quantitativas e qualitativas, mas eu as colocaria, ao menos por agora, como mudanças graduais. O tipo de evolução que experimentamos nos últimos anos é mais de tipo gradual. Se comparamos as informações que, hoje em dia, seguem sendo publicados pelos meios digitais ,e já não me refiro unicamente aos veículos online que são 
versões digitais de diários, televisões e outros, mas sim aos próprios meios nativos digitais. Estes fazem um jornalismo substancialmente diferente do jornalismo que era feito pelos meios não digitais até agora? $\mathrm{E}$ eu digo: substancialmente, não. Porque o tipo de gêneros jornalísticos, as narrativas que são empregadas, as dinâmicas de relação com o público são, até certo ponto distintas. Mas gradualmente distintas, não radicalmente distintas em relação ao que existia anteriormente. Eu não estabeleceria uma diferença radical entre meios digitais e não digitais, mas vejo uma evolução gradual.

A partir do livro Ciberperiodismo en Iberoamérica, uma das coisas que identifiquei é que, até então, não existia uma imagem geral de toda a região: havia pequenos estudo pontuais e

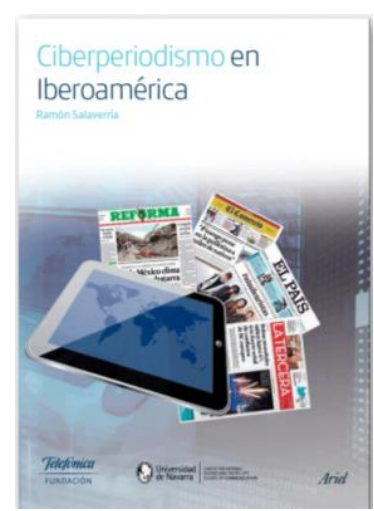
também países nos quais não tinha acontecido nenhum estudo de abrangência ampla. O primeiro livro que fez essa visão geral foi 0 que coordenei e confesso que, o dia que tive o original completo diante de mim no computador (um documento com mais de 600 páginas) e comecei a ler aquele material, me senti um privilegiado. Pensei: "sou a primeira pessoa que está tendo a oportunidade de saber tudo o de importante que aconteceu em todo um continente do mundo em relação a uma disciplina" - que, neste caso, é o ciberjornalismo. Então, uma das coisas que identifiquei nestes estudos, nestes capítulos, é que não podemos falar, todavia, de um ciberjornalismo iberoamericano. Mas podemos falar de um ciberjornalismo na Iberoamérica. É distinto, e é algo que menciono na introdução: a obra poderia ter sido intitulada "Ciberperiodismo Iberoamericano", como por exemplo se fala da nova narrativa latino-americana, quando se falava de [Gabriel] García Márquez, de [Mario] Vargas Llosa. Havia uma série de autores em distintos países, como Colômbia, Peru, Chile, México, que tinham um olhar parecido para a literatura, o "realismo mágico" e diferentes formas de contar a realidade. Aquilo foi interpretado como a "nova literatura latino-americana". O livro se intitula, sutilmente, Ciberperiodismo en Iberoamérica, o que é ligeiramente distinto. Por quê? Porque eu não identifiquei que exista um tipo de jornalismo digital que tenha características comuns na região. Pelo contrário, o ciberjornalismo tem uma 
identidade basicamente nacional e está orientado para os públicos nacionais, mesmo que, comumente, esse público seja migrante. Por exemplo, é muito comum na América Central, em países que tiveram grandes processos de imigração, como Nicarágua, Honduras, El Salvador, que têm grande parte da população vivendo nos Estados Unidos, seus meios digitais são voltados a públicos de seu próprio país tanto dentro de seu território quanto nos EUA, tendo conteúdos para imigrantes. Porém, seguem entendendo não os Estados Unidos como seu território, mas como lugar onde vive suas gentes. Os meios digitais na América Latina são, em grande medida, de âmbito nacional. Isso se diferencia com 0 que já está acontecendo em outros território do mundo, de forma singular nos EUA e em alguns casos na Europa, muito particularmente no Reino Unido. Por exemplo, o New York Times, utilizando o inglês, aspira não somente ser 0 "periódico de Nova York" nem o veículo de referência dos EUA: quer ser o periódico de referência global. $O$ britânico The Guardian pretende ser o veículo em inglês que seja o reflexo da ideologia progressista. No caso do El País, da Espanha, seu lema é "o periódico global" porque pretende sê-lo para o conjunto da América Latina.

PG: Certamente, eles têm uma edição brasileira que está sendo cada vez mais reconhecida, possuindo uma projeção bastante interessante apesar do pouco tempo de existência...

Ramón Salaverría: Exatamente. Há alguns casos, por exemplo, na Espanha, já há uma visão internacional dos meios digitais. Mas na América Latina não há essa situação. Por motivos ideológicos, como no caso da Venezuela, há meios que conectam, a partir de uma visão chavista, pelo menos os países bolivarianos (estamos falando de Equador, de Cuba, os países que estão nesta órbita). Mas do ponto de vista profissional, estritamente jornalístico, não há nenhum empreendimento que pretenda ser uma voz jornalística digital para o conjunto da região. $E$ por isso penso que não se pode falar de ciberjornalismo ibero-americano, mas, na atualidade, de um ciberjornalismo na iberoamérica.

PG: Um dos assuntos que o sr. anda pesquisando é a questão dos modelos de negócios do ciberjornalismo, como estes novos veículos podem se sustentar. Quais seriam, no momento, 
os novos meios jornalísticos que alcançaram êxito? Quais modelos se mostram mais sustentáveis?

Ramón Salaverría: Com certeza, a questão do negócio é o principal condicionante dos meios digitais nos últimos 20, 25 anos. Não foi um problema tecnológico, nem de liberdade de expressão ou de desenvolvimento profissional. A razão pela qual os meios digitais se desenvolveram até o ponto no qual se encontram atualmente é porque sua dimensão empresarial é a que é. Tenho uma hipótese: se o negócio dos meios digitais tivesse se consolidado muito mais do que foi conseguido até aqui, a história do jornalismo nos últimos 20 anos teria sido completamente distinta, porque a transição por parte das empresas jornalísticas ao universo digital teria sido muito mais rápida e proativa, ao passo que foi enormemente defensiva, pelo contrário.

Então, quais são os vetores que eu observo como mais relevantes em relação ao modelo de negócios? Menciono dois: diversificação e mudança de escala. Em relação ao primeiro, os meios digitais não conseguiam trasladar a estrutura de receita que existia nos meios anteriores - tradicionalmente, cerca de $60 \%$ da receita chegava por meio da publicidade e $40 \%$ era conseguido pelas vendas e assinaturas pois, quando os veículos vão ao ambiente digital, isso se quebra. Como não foi possível (até o momento) replicar essa estrutura, foi necessário investir em uma diversificação. Os meios digitais buscaram formas complementares à publicidade (porque esta, por sua parte, foi procurar outros terrenos, como as grandes redes sociais, grandes buscadores).

Assim, apostaram na publicidade, mas também procuraram fórmulas diversas. Em alguns casos, estas foram a venda e a assinatura - que no início não deram nada certo, mas isso, pouco a pouco, começou a mudar. Estas modalidades de pagamento começaram a se popularizar, mas também foram sendo incorporadas outras modalidades de financiamento que não existiam anteriormente. Por exemplo, organização de eventos ou, de forma similar, patrocínios: conteúdos patrocinados, patrocínios públicos e privados, fundações que aportam dinheiro para o sustento de meios nativos digitais - isso é bastante comum na América Latina, por exemplo. De modo que, agora, a quantidade de vias de financiamento dos meios digitais para conseguir se sustentar, manter sua rentabilidade, é muito mais diversa e rica 
do que tinham os meios não digitais.

A segunda transformação seria a mudança de escala. Podemos dizer, na realidade, uma redução de escala. Porque, anteriormente, os meios (imprensa, rádio, televisão) tinham uma escala industrial muito maior, assim como os custos. Então o retorno econômico necessário era muito maior também. Esse tipo de estrutura só poderia ser sustentado com uma receita muito grande. Agora, estamos passando para modelos muito mais econômicos, nos quais com uma equipe humana muito mais reduzida e investimento bem menor (diria incomparavelmente menor) em infraestrutura, qualquer um pode lançar um periódico. Evidentemente, com esses modelos pequenos, o retorno econômico também tende a ser pequeno. Mas é igualmente sustentável e rentável. Então, estamos nesse processo de transição onde os meios grandes já não conseguem manter os níveis de receita que alcançaram no passado, não estão conseguindo trasladar esses níveis ao universo digital e, diante disso, estão crescendo uma quantidade enorme de meios de pequeno escala que, com uma grande diversificação, começam a alcançar, pelo menos, a sustentabilidade.

PG: Pensando nesta situação de pequenos meios e menor escala, o sr. já reflete, em alguns trabalhos sobre o jornalismo no âmbito das indústrias criativas. Como poderíamos pensar o jornalismo dentro deste campo, costumeiramente mais relacionado ao entretenimento?

Ramón Salaverría: Penso que, junto ao desenvolvimento tecnológico, o segundo maior vetor de desenvolvimento dos meios digitais tem relação com as narrativas, com a linguagem. É necessário fazer uma experimentação constante para poder estar em conexão com as demandas dos novos públicos que surgem. Antes eu havia dito que as mudanças dos meios digitais em relação aos anteriores são de tipo gradual, mas estão sendo feitas experimentações para que sejam modificadas as narrativas, as linguagens que foram adotadas no passado para transferi-las até um novo cenário tecnológico, até novas dinâmicas de relação com o público. Grande parte da relação dos meios digitais com as indústrias criativas têm relação com a orientação para a experimentação nas narrativas.

PG: Ainda pensando na nova configuração do ciberjornalismo global, temos a consolidação das

Revista Pauta Geral-Estudos em Jornalismo, Ponta Grossa, vol. 6, n. 1, p. 166-183, Jan/Jun, 2019. 
mídias digitais. Pesquisa recente ${ }^{6}$ realizada no Brasil indicou que, para $55 \%$ das pessoas entrevistadas, 0 Facebook é a própria internet. Muitos pesquisadores se preocupam com essa intenção monopolista da rede de se tornar uma "internet dentro da internet". Dito isso, no ano passado, a Folha de S. Paulo, um dos principais periódicos impressos do país, anunciou que não publicaria mais conteúdo diretamente no Facebook o material pode ser compartilhado, mas não há a postagem por parte do jornal. Até o momento, foi um dos poucos grandes veículos a tomarem essa medida. Como o sr. analisa essa ação, essa "rebeldia" de questionar a hegemonia das redes sociais no consumo de notícias?

Ramón Salaverría: Vejo isso de forma positiva. Evidentemente, é uma ação que apresenta riscos, aliás riscos e custos, que são coisas diferentes. Há o risco de perder uma certa visibilidade e relevância para determinado tipo de público porque se há volumes muito grandes de audiência circunscritos unicamente ao Facebook e alguém se retira da rede, a

${ }^{6}$ A pesquisa pode ser acessada pelo link $\leq$ https://olhardigital.com.br/noticia/55dos-brasileiros-acham-que-o-facebook-ea-internet-diz-pesquisa/65422> possibilidade de se encontrar com esse público em um ambiente digital diretamente praticamente desaparece. $\mathrm{E}$ há custos, porque, obviamente, quando algum veículo perde contato com parte do público, as possibilidades de negócio que podem ser derivadas desaparecem. Mas estes custos podem ser condicionados ou reduzidos se consideramos realmente quais são os termos de relação que se estabelecem entre Facebook e meios de comunicação. E não é uma posição de equilíbrio. Há uma posição absolutamente monopolística e dominante por parte do Facebook em relação aos meios.

Neste sentido, um veículo como a Folha, líder no país mais populoso de um continente, se comparado ao Facebook, é um meio de comunicação pequeno. É um meio grande entre os pequenos (risos). Deste ponto de vista, tem uma maior força do que um meio "pequenopequeno". E me parece bastante sensato que tenha tomado esta decisão. Também é importante considerar que a Folha forma parte de um grupo de comunicação, e assim a decisão do veículo não foi tomada de forma isolada. Provavelmente, é parte do conjunto da empresa jornalística editora de Folha que possui alguns produtos concorrentes

Revista Pauta Geral-Estudos em Jornalismo, Ponta Grossa, vol. 6, n. 1, p. 166-183, Jan/Jun, 2019. 
com o Facebook (tem o UOL, por exemplo). De forma geral, me parece que há distintas ações além da pura

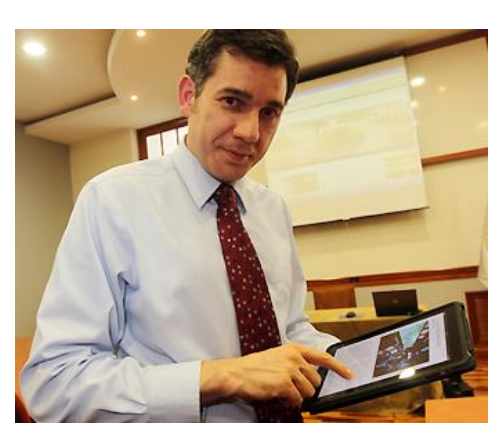

"rebeldia"
que podem
explicar o
motivo pelo
qual a
Folha
decidiu se

retirar da rede social. Verdade seja dita, os acontecimentos sobre dados vazados/vendidos envolvendo 0 Facebook nos últimos anos respaldam a decisão do jornal.

PG: Pensando justamente na questão das redes sociais, vemos nos últimos anos a proliferação do problema das fake news. Este fenômeno poderia ser entendido como um reflexo da falta de transparência dos processos jornalísticos?

Ramón Salaverría: Se analisamos as diferenças entre os meios de comunicação e as redes sociais - e muitos dizem que as redes sociais são os atuais meios de comunicação, pois alcançam audiências massivas - vemos que há uma grande e substancial diferença: os meios de comunicação se fazem responsáveis pelo conteúdo que transmitem, enquanto uma rede social não se responsabiliza pelo conteúdo. O único que interessa é a comunicação em si mesma, o intercâmbio de mensagens entre os próprios usuários. É como se dissessem: "não sou responsável, sequer sou produtor dos conteúdos que são trocados. Sou apenas um provedor de um espaço para que as pessoas falem entre elas". Portanto, com essa diferenciação chegamos ao fenômeno das notícias falsas. Ao Facebook e ao Twitter, a essas plataformas onde são compartilhadas as notícias falsas, na verdade não importa que as notícias sejam falsas - ou não as havia importado até o momento. Porque se é demonstrado que este tipo de material tem altas taxas de compartilhamento e movimento, continua sendo válido. O que interessa ao Facebook é que o conteúdo gere muita participação. Isso tanto é certo quanto é mentira. No caso dos meios de comunicação, interessa que haja uma grande participação por parte do público, mas sempre em relação a informações contrastadas. Esta é a principal distinção. $\mathrm{E}$ me parece uma grande notícia que, nos últimos tempos, tenham surgido polêmicas e discussões a respeito das redes sociais e sua responsabilidade no controle deste tipo de dinâmica. Porque elas se beneficiam

Revista Pauta Geral-Estudos em Jornalismo, Ponta Grossa, vol. 6, n. 1, p. 166-183, Jan/Jun, 2019. 
da presença deste tipo de material, mas não se responsabilizam. Meu ponto de vista é: alguém que se beneficia de algo precisa ser, também, responsável que aquilo corresponda à realidade, como no caso dos meios jornalísticos.

PG: E em relação a justamente esta diferença, entre o consumo das redes sociais e o do jornalismo, que são universos diferentes, como o sr. acha que a chamada educomunicação pode ser trabalhada para uma "alfabetização" do público? 0 conhecimento das pessoas acerca destes processos seria o melhor caminho? Ou outras possibilidades, como o fortalecimento de novas iniciativas jornalísticas?

Ramón Salaverría: Nos últimos tempos, quando estão ganhando evidência estas notícias e problemas, surgiu esta pergunta sobre como enfrentarmos esses problemas. E, até agora, parece que há duas alternativas principais: uma alternativa é tecnológica, é lutar contra a tecnologia por meio da tecnologia - se a tecnologia favorece o desenvolvimento das notícias falsas, vamos criar tecnologias que contrariem essas dinâmicas, como inteligência artificial, filtros, meta moderação, para que estes conteúdos desapareçam. Essa seria uma das fórmulas, de caráter imediato. Outra fórmula seria uma fórmula legal, legislativa. Quer dizer, através do desenvolvimento de leis, de políticas, para conseguir um maior controle das redes sociais.

Eu tenho minhas reservas contra estas duas possibilidades de atacar as notícias falsas e outros tipos de problemas das redes digitais porque, rapidamente, o que supostamente poderia ser uma medida para resolver algo converte-se em problema. Quero dizer, se colocamos uma tecnologia para contrapor outra, talvez esta que estejamos impondo tenha efeitos negativos. $E$ a respeito das medidas legislativas, orientadas a controlar as redes, eu, como bom jornalista, entendo que a liberdade de imprensa é muito importante e as possibilidades por parte dos poderes públicos, dos governos, aproveitem essa inércia para controlar mais as atividades na rede são enormes.

Há um terceiro tipo de medidas, das quais se fala muito pouco, que são as medidas educativas, a alfabetização digital. O que ocorre com as medidas educativas? Seu resultado não é imediato - nunca é imediato, a educação não tem esse tipo de resultado. Mas tem um resultado diferente. No longo prazo, 
este é o resultado que realmente incide. Então, parece que deveria haver um modelo centrado em medidas tecnológicas e legislativas, até certo ponto tudo o que seja estritamente necessário, mas não mais que isso. Mas, sobretudo, onde deveria incidir é sobre as medidas educativas. Neste sentido, faço uma última reflexão: nos últimos 20 anos, falou-se bastante de alfabetização digital. Esta, porém, foi entendida unicamente como domínio das ferramentas digitais. Domínio do computador, do software... mas não realmente como podemos fazer um uso responsável e produtivo de essas ferramentas. A alfabetização se orienta, em geral, a ser uma mera instrução técnica. Como podemos utilizar essas ferramentas? No âmbito das notícias falsas, mais importante ainda que explicar como funciona uma máquina, um computador, seria importante alfabetizar digitalmente sobre como se deve ler as notícias em âmbito digital. Em que consiste contrapor uma fonte, como se identifica uma fonte credível em um meio digital, como podemos certificar um dado? Quais são os alertas intelectuais que temos que ter diante de uma informação que circula nas redes sociais? Que coisa convém ou não convém repercutir nos meios como
Twitter ou Facebook? Esse tipo de alfabetização me parece que seria necessário trabalhar nas escolas $e$, desafortunadamente, me parece que muito pouco é feito, praticamente nada.

\section{PG: Como as escolas de Jornalismo estão abordando a questão?}

Ramón Salaverría: Em virtude do meu trabalho e atividades internacionais, tive a oportunidade de visitar muitos países e universidades, conhecer muitos colegas em congressos. Conheço muitas realidades sobre 0 ensino de ciberjornalismo na América Latina, tenho informações bastante amplas acerca das dinâmicas de ensino na região. Esta era uma das seções que aparecem em todos os capítulos do livro, todos têm alguns parágrafos dedicados à formação dos jornalistas. E minha sensação, faz 20 anos - e que agora é um pouco menor, mas segue sendo parecida - é de que, em muitas escolas de Jornalismo, o que se faz é uma mera instrução técnica, um simples "adestramento" tecnológico: como se utilizam determinados softwares, sistemas de conteúdo, de publicação.... ferramentas que permitem a produção de conteúdo para na internet. $E$ há muitas escolas e professores que concentram todo o seu sistema de 
ensino em uma instrução técnica sobre essas ferramentas. Me parece que isso é necessário, mas certamente não é 0 mais importante. O fundamental em uma escola de Jornalismo é ensinar valores, ensinar princípios, ensinar modos, linguagens... e é nisso que eu, pessoalmente, tenho tratado de enfocar minha investigação - e portanto, minha docência. Sou um professor de tecnologia mas ensino muito pouco sobre tecnologia, só o imprescindível. Procuro que a maior parte do meu ensino se concentre em aspectos que tenham a ver com a reflexão, com critérios, valores, que é, a meu modo de ver, o que é permanente.

PG: 0 sr. está com um projeto atualmente com financiamento da União Europeia sobre a questão do Big Data no jornalismo. Quais são seus objetivos com esta pesquisa?

Ramón Salaverría: Este é um projeto amplo. Não estamos somente nós da Universidade de Navarra, esses grandes projetos são concedidos a consórcios conformados por várias instituições. O centro coordenador é a Dublin City University (Irlanda), mas, além da nossa, fazem parte também Universidade de Amsterdã (Holanda), Universidade de
Toulouse (França) e Universidade de Tessalônica (Grécia). Ademais destas cinco, estão alguns meios de distintos países europeus, tanto grandes, como a britânica BBC, e pequenos meios, em geral nativos digitais, como no caso do Confidencial, da Espanha. Conformamos um consórcio que agrega meios de diferentes tipos.

$\mathrm{E}$ em que consiste $\mathrm{O}$ projeto? Basicamente, temos a finalidade de formar 15 "super especialistas" europeus ou na Europa (não precisam ter nascido no continente, mas a investigação acontece aqui) sobre as novas tendências do jornalismo com o objetivo que essas pessoas, com base na qualificação que vão alcançar com bases neste projeto, possam contribuir com o fortalecimento da indústria jornalística do continente europeu com o aproveitamento das novas tecnologias. Em muitos casos, a visão por parte dos meios tem sido uma visão melancólica ou com bastante "saudade" dos "velhos bons tempos". E tem existido uma visão um pouco suspeitosa a respeito das tecnologias como disruptivas de todo o sistema de jornalismo de qualidade que antes existia.

Bom, nossa visão enquanto consórcio evidentemente não é esta. Nossa visão é: "como podemos utilizar as tecnologias 
atuais e as que vão chegar para conseguir recuperar a relevância do jornalismo no marco das sociedades democráticas?" Não é dar as costas, portanto, às tecnologias, mas pelo contrário. Como podemos utilizar as tecnologias esses valores tradicionais do jornalismo? E o projeto, ao financiar 15 investigações doutorais repartidas entre as cinco universidades citadas, será realizado de modo que investigaremos 15 assuntos particulares, e cada uma das bolsas de doutorado terá um tema designado e os investigadores que obtiverem cada uma terão que fazer um trabalho de doutorado em três anos em condições magníficas para poder fazer uma investigação de máximo nível mundial e que os permita converterem-se em referências internacionais deste determinado assunto.

PG: Um projeto realmente grandioso...

Ramón Salaverría: Certamente. Para nós, é uma oportunidade histórica. Trabalhamos em vários projetos, participamos de algumas redes europeias, mas nunca havíamos contado com um projeto de estas dimensões. Estamos falando de um projeto de cerca de quatro milhões de euros, é um financiamento impressionante para qualquer pesquisa. Mas isso acontece porque os objetivos são muito ambiciosos e as pessoas que estarão investigando - particularmente, essas 15 pessoas selecionadas - serão certamente privilegiadas, haja visto que terão muitas condições econômicas e recursos de pesquisa sonhadas por qualquer acadêmico. Ao mesmo tempo, passarão por uma situação enormemente exigente, porque os resultados que são esperados estarão, também, à altura do investimento que está sendo feito.

PG: Uma última pergunta: no início de 2018, o sr. escreveu um texto no qual afirma: "desde as tecnologias de inteligência artificial até a 'Internet das Coisas', uma onda de novas tecnologias convertirá o jornalismo que conhecemos em algo ubíquo". A tendência é que, no futuro, as notícias sejam produzidas por inteligência artificial e também multissensoriais, conforme o sr. colocou. Suscitam-se algumas reflexões: onde se encontrará 0 ser humano nesta situação? E como a academia deve responder a este novo estágio, quais formas pelas quais a academia tenta abordar essa nova situação?

Revista Pauta Geral-Estudos em Jornalismo, Ponta Grossa, vol. 6, n. 1, p. 166-183, Jan/Jun, 2019. 
Ramón Salaverría: Há uma postura lógica e, por outra parte, de receio a respeito da tecnologia por várias razões. Em primeiro lugar, podem ser tecnologias que substituam postos de trabalho de jornalistas e isso é visto com certa suspeita. E também porque há preocupação de que as tecnologias gerem um tipo de conteúdo não determinado por valores jornalísticos tradicionais, mas condicionados por interesses comerciais e ideológicos. Basicamente, teme-se que seja dada cada vez maior relevância ao quantitativo em face do qualitativo.

Eu diria aos investigadores a não terem sempre essa posição de suspeita, de distância a respeito das tecnologias. Deveria-se ter uma posição muito mais proativa, sem perder de vista a postura crítica diante do avanço tecnológico. É necessário, também, ser feito um esforço para se avaliar quais são as possibilidades, elementos positivos para a profissão jornalística, para a qualidade da informação graças à utilização das tecnologias. É difícil encontrar este ponto intermediário, de distância e, ao mesmo tempo, vontade de experimentação. É o que, pessoalmente, tenho tratado de aplicar durante minha carreira como investigador e professor. E o que gostaria é que, nos próximos anos, com essas tecnologias que efetivamente estão começando a chegar - e que entendo que irão se multiplicar cada vez mais em nosso entorno - nós, professores, compreendamos que temos uma obrigação diria quase moral de nos aproximarmos destas tecnologias e entendê-las. Ver quais são os problemas, mas também identificar quais são suas oportunidades e as alternativas.

Recebido em: 25/11/2018.

Publicado em: 23/07/2019. 